\title{
El Bildungsroman para no especialistas: Un intento de aclaración
}

Fecha de recepción: 19/5/2020.

Fecha de aceptación: 20/10/2020.

\section{Resumen}

El artículo ${ }^{2}$ discute y problematiza el empleo del término "Bildungsroman", tanto el uso indiscriminado, impreciso, que se percibe en cierta parte de la crítica norteamericana como las visiones restrictivas (y de tendencia nacionalistas) de la Germanística, producto de la canonización guillermina, que pretenden confinar el subgénero al territorio alemán. Con el fin de restaurar el contenido teórico y crítico, además de su utilidad en tanto categoría histórico-literaria, en el presente artículo se circunscribe la aplicabilidad del término Bildungsroman a las novelas que mantengan alguna relación, sea de identificación como de parodia o crítica, con el concepto humanista y temprano burgués de Bildung. De este modo, la definición propuesta abarca desde el arquetipo histórico, Los años de aprendizaje de Goethe, como las denominadas antinovelas de formación románticas hasta las novelas de Herman Hesse y Thomas Mann, ya en las primeras décadas del siglo XX.

1 Jefe del Departamento de Lenguajes y Literaturas Germanas en la Universidad de Yale. Fue nombrado en 2001 profesor emérito por la misma universidad. Sus trabajos de investigación abarcan la obra de Heine, el período de Vormärzy los realistas alemanes decimonónicos. Es uno de los más reconocidos germanistas norteamericanos. 


\title{
The Bildungsroman for Nonspecialists: An Attempt at a Clarification
}

\begin{abstract}
This article discusses and problematizes the usage of the concept of Bildungsroman; both the indiscriminate, imprecise use perceived in part of the North American critics, as well as the restrictive (and nationalistic-driven) visions of the Germanistic, a product of Wilhelmine canonization, that confine the term to the German territory. With the aim to restore its theoretical and critical contents, in addition to its utility as a historic and literary category, it circunscribes the applicability of the term Bildungsroman to the novels that mantain any type of relation -be that of identification as of parody or refusal- with the humanistic, early-bourgeoise concept of Bildung. In this manner, the definition proposed encompasses the historic arquetype, Goethe's Wilhelm Meister's Apprenticeship the romantic Antibildungsromane up to the novels of Herman Hesse and Thomas Mann in the first decades of the twentieth century.
\end{abstract}

Keywords: Bildungsroman; Bildung; terminology; Second Reich.

En uno de esos almanaques que sirven para aprender nuevas palabras y conceptos cada día (tal es uno de los desesperados recursos que empleo para exponer a mis hijos a la cultura o Bildung), apareció un día la palabra Bildungsroman. Allí era definida como "una novela sobre el crecimiento moral y psicológico del personaje principal”. Luego seguía un ejemplo ilustrativo: “Hijos y amantes de D. H. Lawrence es un Bildungsroman con contenido fuertemente autobiográfico". Una persona con más curiosidad que la que muestran normalmente mis hijos en estos asuntos quizá se preguntase por qué el ejemplo de un término tan obviamente alemán es una novela inglesa.

Pero, por lo demás, la definición parece inofensiva, no representa desafío alguno, aunque también parece dudosa su utilidad en un trabajo serio sobre literatura. Si creásemos una lista con todas las novelas de literatura occidental que se ajustan o están tangencialmente relacionadas con esta definición, estaríamos ocupados por demasiado tiempo. Uno podría pensar que un concepto que es definido de tal manera, que evidentemente fracasa en delimitar un género novelístico, con toda seguridad debe ser dejado de lado. Sin embargo, como saben todos los que trabajan en el campo de la literatura alemana, y algunos fuera de este campo, hay mucho más que esto en el término.

Las terminologías definitorias de la crítica e historia literarias generan problemas de un modo crónico: cuanto más técnicas son, más sencilla parece su aplicación. Probablemente no tengamos mucha dificultad en distinguir un yambo de un dáctilo, pero si una línea en particular es dactílica o anapéstica puede ser objeto de disputa. Sin duda la identificación de un soneto no es algo 
El Bildungsroman para no especialistas: Un intento...

controversial, pero, en este caso, el término es en cierto sentido tautológico, en la medida que identificamos un poema como un soneto porque un soneto es un poema de ese tipo.

Cuando se trata de clasificaciones de período y género, las dificultades se multiplican, porque son términos de historia literaria que, por tanto, están atravesados por las inseguridades de la historiografía en general y, con frecuencia, cargados de ideología. El concepto de barroco, originalmente un término despreciativo aplicado a la literatura alemana del siglo XVII, resulta engañoso y limitado para muchos estudiantes de la época, en especial porque analizado en detalle el barroco se asemejaría más a un tardío Renacimiento alemán. Además, siempre hay quienes encuentran que estos términos son ilegítimos, que producen interferencia en la crítica al mellar sobre la atención y conciencia crítica de la especificidad de los escritores y sus obras.

Cuando estos términos amenazan con transformarse en lo que los estudiantes de Ivy League 3 llamaban "fritos" (cepts) -mutilaciones teóricas de opiniones heredadas que substituyen al análisis de primera mano-, la tentación de vetarlos de toda investigación consciente es comprensible. Algo similar ocurre con las clasificaciones genéricas: después de algunos cientos de años de deliberación sobre la Novelle, ${ }^{4}$ tema que ocupó enormemente a los germanistas y que no muestra signos de un consenso futuro, algunos especialistas pueden llegar a rendirse y declarar sin más que la Novelle es solo una ficción en prosa de extensión intermedia y nada más.

Hay, sin embargo, razones por las que estos gestos de despejar el terreno no son exitosos en su conjura de esta terminología problemática. Después de haber sido descartados, es probable que descubramos por qué desearíamos emplear nuevamente estos conceptos. La literatura alemana del siglo XVII, con toda su enérgica variedad y tendencias centrifugas, es una época de historia literaria con características discernibles, marcada en sus relaciones internas por una resurrección asombrosamente rápida, eficiente y consciente de las posibilidades de la poética en vernáculo, en alemán; y en sus relaciones externas por su integración a la época de la Guerra de los Treinta Años, que fue percibida en ese momento y mucho tiempo después como un holocausto virtual que afectó profundamente el tono literario de toda la época. El término "barroco" puede ser un signo arbitrario que no tiene otro significado que la totalidad del fenómeno literario que encapsula, pero esa totalidad, dinámica y diversa como es, efectivamente existe. La Novelle sigue insistiendo en su existencia, en parte porque ciertos autores a lo largo de las generaciones se han obsesionado con las posibilidades

3 Con Ivy League se designa a ocho universidades del noreste de Estados Unidos. Las universidades de Brown, Columbia, Cornell, Dartmouth, Harvard, Pennsylvania, Princeton y Yale reciben este nombre por las hiedras (ivy) que cubren las paredes de gran parte de estas instituciones. (Nota del trad.)

4 A diferencia del lugar algo difuso que parece tener la novela corta en español, clasificación usada con frecuencia para denominar sin demasiada precisión una extensión intermedia entre novela y cuento, en el ámbito germánico, Novelle no supondría una mera clasificación cuantitativa sino cualitativa, con sus discutidas características inherentes y peculiares a la forma. Cfr. Vedda, M. (2001). Introducción. En Aren, F., Rotemberg, S., Vedda, M. (eds.). Antología de la novela corta alemana. De Goethe a Kafka, pp. 5-24. Buenos Aires, Colihue. (Nota del trad.) 
y características formales del término (mientras que otros autores a su vez han ignorado totalmente el asunto, clasificando indistintamente ficciones en prosa como Novelle, Roman o Erzählung). ${ }^{5}$

No tiene nada de malo emplear tales términos e investigar su utilidad, siempre y cuando estén empleados en su instrumentalidad heurística y no sean confundidos con formas ideales anteriores a la experiencia literaria. Sin embargo, cuando no son solo términos genéricos sino que también conllevan implicaciones histórico-literarias, es necesario estar atento a las fuentes y bases de la historia literaria que pretenden ordenar, y no aceptarlos como opinión heredada.

En este sentido, el término Bildungsroman supone un conjunto de peculiares y hasta cierto punto confusos obstáculos. No es mi propósito entrar en esta historia en detalle; existe mucha bibliografía sobre estos asuntos. Más bien me gustaría mostrar cómo el término está asociado con interpretaciones erróneas generalizadas en el desarrollo de la literatura alemana del siglo XIX; interpretaciones que inicialmente fueron generadas internamente en el proceso de canonización alemán, que tuvo como resultado una visión distorsionada de la historia literaria alemana y, en cierta medida, de su cultura en general para otras disciplinas literarias, siempre que estén interesadas en temas germanísticos. Lo que está en discusión aquí son dos proposiciones. Primero, que el Bildungsroman es una forma peculiarmente alemana. Segundo, que fue la forma dominante de la novela alemana en el siglo XIX y que en cierto grado habría aislado al género de sus contrapartes en otros países hasta su reincorporación a la comunidad literaria europea a través de los logros, como suele señalarse, de Theodor Fontane y Thomas Mann.

La primera de estas proposiciones no es universalmente reconocida, como podemos fácilmente ver en la definición corriente con la que abrí este trabajo; pero que esto sea así también es evidencia de un vasto desorden en el empleo del término y en particular de una confusión respecto a si debe ser entendida de manera genérica o históricamente. Inicialmente el término no fue de ninguna manera ideado para definir un tipo de novela europea. En su historia moderna, que comienza con Wilhelm Dilthey en el momento de la fundación del segundo Reich, el término reivindica una tradición alemana particular cuyos orígenes filosóficos se remontan a la era clásico-romántica de la Humanitätsphilosophie y cuyo arquetipo literario es Los años de aprendizaje de Wilhelm Meister (Selbmann, 1984:21).

Es precisamente este el período en que la historia literaria alemana estuvo sujeta a un elaborado, perdurable e influyente proceso de recanonización a partir del que Goethe y los románticos se convirtieron en el eje de la tradición cultural y, finalmente se vincularon con el Neoromanticismo, lo cual resultó en el relegamiento de una gran parte de la vida literaria del siglo XIX a un olvido relativo.

5 Es decir, no se distinguiría entre novela corta (Novelle), novela (Roman) y cuento o relato (Erzählung). (Nota del trad.). 
Esto tuvo lugar bajo intensas presiones nacionalistas e ideológicas que querían demostrar la existencia de un Sonderweg, de un camino singular tomado por la cultura alemana, que no solo sería diferente sino, en algunos aspectos, superior a los desarrollos de otras culturas tanto occidentales como orientales. ${ }^{6}$ Entre los muchos testimonios de esta proposición, el artículo "Bildungsroman" de Hans Heinrich Borcherdt, publicado en la Enciclopedia de la literatura alemana, se coloca en un lugar prominente: el género es identificado allí como "la forma principal de la novela alemana", que "como ninguna otra forma poética es capaz de revelar los rasgos esenciales, decisivos del carácter alemán” (Borcherdt, 1958: 175).

En cuestiones de este tipo es importante recordar que tradicionalmente en Alemania el estudio de literatura no fue un segmento separado de las humanidades, como ha sido en nuestras universidades, sino que fue subsumido bajo la disciplina integral de la Germanística, el estudio, refuerzo y transmisión de los presuntos valores culturales de la nación. Por lo tanto, indagar sobre la definición del Bildungsroman no es un problema confinado al discurso académico, sino que se extiende a la autocompresión ideológica de la cultura en su totalidad. Se pueden encontrar ejemplos particularmente llamativos de esta amplitud en las carreras de Herman Hesse y Thomas Mann. A diferencia, supongo, de la mayoría de los escritores alemanes, ninguno de los dos tuvo una educación universitaria; de hecho, ninguno terminó la escuela. Con todo, los encontramos-cada uno a su manera- intentando ajustarse al concepto canónico de Bildungsroman.

Hesse fue excepcionalmente ambicioso en su idea de continuar la gran tradición literaria, que concebía como pronunciadamente goetheana y romántica. Como he comentado en otro lugar, "con la excepción de Dostoievski y Nietzsche, apenas hay artistas o pensadores que Hesse mencione que hayan vivido después de la década de 1830" (Sammons, 1973: 118s.). Consecuentemente, escribió una novela tras otra que pueden ser asociadas con la definición de Bildungsroman de la Germanística guillermina, basada en Los años de aprendizaje de Wilhelm Meister: Peter Camenzind, Demian, Siddhartha, Narciso y Goldmundo y El juego de abalorios. Se ha afirmado, en relación con el Demian, que

mediante el uso de esta forma heredada, Hesse se coloca conscientemente en una tradición narrativa con la que se sentía en sintonía. Aunque la forma ha inspirado novelas no alemanas [...], el Bildungsroman es un género específicamente alemán y constituye la principal contribución de Alemania a la novela europea (Ziolkowski, 1965: 90).

Mann, por otro lado, reprodujo la forma, como era su costumbre, mediante parodias en tono serio como La montaña mágica, Doktor Faustus y José y sus hermanos; y en una parodia considerablemente menos seria, Confesiones del estafador Felix Krull. Su sentido del status del género en sí, sin embargo, estaba totalmente conforme con la visión canónica. En 1916, en un ensayo sobre la novela autobiográfica, Mann escribe: 


\begin{abstract}
Ahora bien, hay una variante de la novela que es alemana, típicamente alemana, legítimamente nacional, y esta es precisamente la autobiográficamente realizada novela de formación [Bildungsroman] y de desarrollo [Entwicklungsroman]. Estamos también de acuerdo, creo, en que el predominio en Alemania de este tipo de novela, el hecho de su particular legitimidad nacional, está estrechamente relacionado con el concepto alemán de humanidad, de la que, siendo ella un producto de una época en la que la sociedad se desintegró en átomos y que hizo de cada ciudadano un ser humano, el elemento político ha estado desde siempre casi completamente ausente (Mann, 1960: 702).
\end{abstract}

En el estado de ánimo nacionalista de Consideraciones de un apolítico (1918), por su parte, aseveró que el concepto de Bildung en sí mismo "es específicamente alemán; proviene de Goethe, quien le dio su carácter plástico-artístico; por él ha recibido su sentido de la libertad, de la cultura y de devoción por la vida [...] y gracias a él ese concepto fue elevado al rango de principio educacional en Alemania como en ningún otro pueblo" (Mann, 1978: 517). ${ }^{7}$

Con respecto a la segunda proposición, el supuesto predominio de la forma del Bildungsroman sobre los demás géneros novelísticos alemanes en el siglo XIX, se podría suponer que ha sido ejemplificado hace mucho tiempo con la discusión de sus numerosos exponentes. Pero este no ha sido el caso; para el siglo y un cuarto que va desde la aparición del Romanticismo hasta la Primera Guerra Mundial, apenas más de una docena de títulos han sido comúnmente incluidos en este subgénero y gran parte de la discusión se centró en el único y arquetípico exponente: la novela de Goethe, Los años de aprendizaje de Wilhelm Meister. ${ }^{8}$ Aquellos que no están familiarizados con las peculiaridades de los tradicionales estudios sobre literatura alemana pueden pensar que estoy inventando esto, pero no es así: he narrado mi búsqueda desconcertante sobre este género esquivo en otro lugar (Sammons, 1981) y solo deseo recapitular aquí el resultado al que llegué.

El Bildungsroman alemán emerge a finales del siglo XVIII, florece brevemente en la época de Goethe y el Romanticismo y -con la excepción de contados y dispersos exponentes, algunos de los cuales fueron rescatados de la oscuridad en el proceso de canonización guillermina- tiene una existencia subterránea en el siglo XIX para luego resurgir con el Neorromanticismo en nuestro propio siglo (Köhn, 1969: 3). Pero tampoco este canon reducido está libre de inseguridades. Muchos de los ejemplos románticos estarían más claramente comprendidos por el concepto de Antibildungsroman; mientras que los exponentes del siglo XIX -con la excéntrica y aislada excepción de El verano tardío (1857) de Stifter-, con sus expectativas disminuidas notoriamente respecto a las posibilidades del yo, del sujeto en el mundo, parecen privadas del optimismo que era una característica esencial del concepto goetheano

7 La traducción castellana disponible ha sido ligeramente modificada. (Nota del trad.)

8 Esta tendencia ha continuado en tiempos relativamente contemporáneos. Por ejemplo, M. M. Bajtín, en su lamentablemente interrumpido esfuerzo por desarrollar una investigación teórica sobre el género del Bildungsroman, reconocía que no era puramente alemán (Bajtín, 1995); pero, dado el carácter fragmentario del estudio, solo llega a discutir con detenimiento Los años de aprendizaje de Wilhelm Meister. 
El Bildungsroman para no especialistas: Un intento...

y humboldtiano de Bildung. Incluso se ha cuestionado la identificación del texto arquetípico, Los años de aprendizaje de Goethe, como un Bildungsroman (May, 1957: 137).

Considerando cuán frágil es este supuesto genérico frente a cualquier tipo de examen profundo y consciente, no sorprende que la primera investigación seria, moderna e integral de este problema llegara a la conclusión de que el Bildungsroman es "un género incumplido" (Jacobs, 1972: 21). Resulta evidente que esta afirmación fue controversial, porque fue atacada enfáticamente desde entonces. ${ }^{9}$ Jacobs ha sido acusado de diseñar una camisa de fuerza normativa para después descubrir, como era de esperar, que no calzaba con ninguno de los textos. Pero pienso que él ha hecho un verdadero aporte al someter un mito de la historia literaria a una investigación analítica que ha liberado el estudio de la novela alemana decimonónica. Siguiendo una línea esbozada por Lothar Köhn (1969: 78), Rolf Selbmann diferenció entre Bildgungsmotiv, Bildungsgeschichte y Bildungsroman, ${ }^{10}$ haciendo que el elemento de Bildung sea más temático que genérico, en el sentido de que enriquece el tejido de la historia literaria. Harmut Steinecke propuso el término Individualroman para la novela que toma la forma de una ficción biográfica o autobiográfica (1984: 27), una sugerencia que ya posee gran tracción y que está ayudando a liberar a la novela alemana de su peculiar status "nacional" para reconducirla al contexto internacional de la novela occidental al que pertenece.

Algunos otros académicos han comenzado a preguntarse lo siguiente: si el Bildungsroman no se encuentra en cantidades abrumadoras en la Alemania decimonónica, qué tipo de novelas sí encontramos en ese siglo. Es un tema que hasta 1969 era designado como terra incognita (Köhn, 1969: 89). El resultado fue una serie de estudios sobre "otras, bastante ocultas, tradiciones novelísticas" (Selbmann, 1984: 28), como la novela histórica, política o social en Alemania desde el declive del Romanticismo hasta la llegada de Theodor Fontane, esto es, desde el período de la Joven Alemania y atravesando el realismo programático. ${ }^{11}$ Autores descanonizados pero que, en su propio época, tenían reputación nacional, y, en algunos casos, internacional, vuelven a ser ahora visibles: Willibald Alexis, Charles Sealsfield, Karl Gutzkow, Berthold Auerbach, Friedrich Gerstäcker, Wilhelm Raabe, Gustav Freytag, Louise von François, Friedrich Spielhagen, y espero que pronto otros, como Fanny Lewald, Hermann Kurz o Karl Emil Franzos, sigan este mismo camino. Dicho sea nuevamente, se trata de reconectar la novela alemana con la europea: efectivamente, este proceso constituye el comienzo de una completa re-escritura de la historia literaria alemana del siglo XIX.

Mi intención no es continuar con estos desarrollos, sino considerar cómo el concepto de Bildungsroman opera en la percepción de la literatura alemana fuera del campo de la Germanística, donde creo que las investigaciones citadas son

9 Cfr. Swales (1978: 12); Selbmann (1984: 26 y 39).

10 Motivo de formación, historia de formación y novela de formación, respectivamente. (Nota del trad.)

11 Cfr. Adler (1980); Denkler (1980); Friesen (1972); Huber (1978); Jackson (1981); Kafitz (1978); Kolbe (1968); Lützeler (1983); Worthmann (1974). 
desconocidas completamente. El concepto mismo de Bildungsroman no es, con todo, desconocido; se lo puede encontrar en todo tipo de lugares, no solo en aquellos almanaques que sirven para ampliar el vocabulario. Para comenzar, parece claro que si el término puede ser aplicable a todo el universo discursivo de la literatura en general, las iniciales afirmaciones sobre su peculiaridad germanidad se disuelven. Podría preguntarse uno: “YY qué supone esto?” Bueno, una consecuencia, me parece, es la introducción de una incontrolable arbitrariedad en el empleo el término, lo que a su vez suscita la pregunta sobre la necesidad de conservarlo en absoluto. Veamos un ejemplo que cayó en mis manos mientras escribía esto, de una reseña de Irving Howe sobre una novela árabe-israelí:

\begin{abstract}
En su totalidad, Arabescos parece seguir el patrón del Bildungsroman y es aquí donde hay problemas. El patrón es suficientemente conocido: un joven, educado hasta la incomodidad con sus orígenes, abandona su pueblo o aldea, llega a una metrópolis para vivir la experiencia del dinero, de las mujeres y de la disolución urbana; y luego, más triste pero quizá más sabio, regresa a su hogar. Balzac usó este esquema, pero con un inteligente giro al final de Las ilusiones pérdidas; Dickens lo adaptó en Grandes esperanzas; Balanchine lo transpuso en geniales movimientos en El hijo pródigo. ${ }^{12}$ Pero no funciona del todo en los Arabescos [...] (Howe, 1988: 5).
\end{abstract}

Podemos notar aquí como un detalle adicional un clásico gesto crítico, conocido para aquellos familiarizados con el tema: el Bildungsroman analizado en detenimiento resulta no ser un Bildungsroman; el autor, pues, fracasó en la realización de esta forma. Un problema mayor es que difícilmente exista una novela alemana que pueda o haya sido calificada como un Bildungsroman y que logre adaptarse a la definición de Howe, salvo Enrique el verde de Gottfried Keller y quizás la temprana obra de Wilhelm Raabe, La gente del bosque. Después de que generaciones enteras, dentro y fuera de Alemania, hayan considerado a lo largo de cien años que el Bildungsroman es la forma característica alemana, ¿debe este concepto ser suprimido totalmente de la historia literaria alemana para ser aplicado, en cambio, en fenómenos que le son completamente ajenos? Esto sería algo irracional.

La despreocupación terminológica es característica también del libro de Jerome Hamilton Buckley, Temporada de juventud: El Bildungsroman de Dickens a Golding. Es difícil descifrar por qué Buckley quiere utilizar la palabra Bildungsroman en tanto él mismo afirma: "He estado constantemente impresionado por la incomodidad del término alemán cuando se lo aplica a la literatura inglesa" (1974: 7). El autor no está interesado en darle al término alguna definición rectora que proporcione un sostén teórico para sus interpretaciones; es tan solo un repositorio vacío: "Ahora uso la clasificación en su sentido más amplio como sinónimo conveniente para la novela de juventud o aprendizaje" (Buckley, 1974: 13). Si es así, ¿por qué no utilizar el término más general, menos cargado teóricamente de Entwicklungsroman, o, dado el caso, cualquier otro signo arbitrario?

12 El hijo pródigo (1929) es un ballet creado por los Ballets Rusos de Diáguilev, con música de Serguéi Prokófiev, libreto de Borís Kojnó y coreografía del mencionado George Balanchine. (Nota del trad.) 
El hecho de que Buckley no esté interesado en las potencialmente útiles implicaciones del término es algo que queda en evidencia por su insuficiente trato con el arquetipo histórico, el Wilhelm Meister de Goethe. El conocimiento de Buckley parece estar mediado principalmente por Carlyle ("exposición aburrida y apartes excesivos"; "extensos e irrelevantes cuentos interpolados y grandes tramos de nublado ocultismo" [!]; "retórica muy verborrágica") (1974: 10 y 12). Por supuesto, uno no está obligado a admirar el Wilhelm Meister, pero negarse a acceder a él midiéndolo contra cánones valorativos con los que no tiene nada que ver, para luego apropiarse de un término histórico literario que en gran medida fluye de dicha novela parece ser poco más que una leve arrogancia provincial.

Esta apropiación errónea tiene la consecuencia de dejar a la novela alemana en una encrucijada. Por un lado, cuando el término es empleado indiscriminadamente a un tipo de novela vasto y amorfo que supuestamente puede ser descubierto en la historia mundial de la novela desde sus comienzos más tempranos, se pierde de vista la específica tradición alemana. Cuando, por otro lado, los viejos reclamos relativos a que el Bildungsroman es el modo alemán dominante son tomados en serio, es la novela alemana la que emerge como algo provincial. No es que el término, aplicado a la literatura alemana por quienes tienen cierto conocimiento al respecto, tenga normalmente connotaciones despectivas; el Bildungsroman suele ser reconocido como una valiosa contribución alemana al género novelístico. Pero mientras que los alemanes de la vieja generación como Thomas Mann veían la presunta peculiaridad nacional en el Bildungsroman como una marca de distinción o incluso de superioridad sobre Este y Oeste, fuera de la Germanística esto implica un déficit.

Así, a nosotros, los germanistas, se nos pregunta: ¿dónde están los Dostoievski, Turguénev, Tolstoi, Balzac, Stendhal, Zola, Dickens, Thackeray, George Eliot, Hawthorne, Melville alemanes? En otras palabras, se percibe en los alemanes una auto-exclusión de una gran época en la historia de la literatura, la del gran realismo: un modo que expandió enormemente los límites del arte de la ficción al mismo tiempo que produjo obras que fueron -y en muchos casos, todavía son-amplia, entusiasta y largamente leídas en sus propias sociedades y también en otras países, con frecuencia por medio de traducciones. Por nuestra parte, cuando nos piden que nombremos una novela importante de mediados de siglo XIX escrita en lengua alemana, estamos condicionados a ofrecer El verano tardío de Stifter, novela cuyos lectores, si tenemos en cuenta toda la segunda mitad del siglo XIX, podrían, creo yo, haber cabido en un solo salón de tamaño moderado. Así, el proceso de canonización de tipo nacionalista del siglo XIX, con sombría justicia, tuvo como resultado la desaparición de la literatura alemana posromántica, premodernista ${ }^{13}$ de la competencia de los estudios literarios en general y de la apreciación en nuestra sociedad.

13 Se conoce por modernism a la literatura europea y norteamericana entre los últimos años del siglo XIX y las primeras tres o cuatro décadas, cuando menos, del siglo XX. Por sus fácilmente reconocibles figuras literarias y críticas, también se lo ha llamado modernismo anglosajón, para diferenciarlo más claramente del modernismo latinoamericano. Aplicado a la literatura en lengua alemana, comprendería autores tan diversos como Rilke, Kafka, Benn, Brecht y los mencionados por Sammons, Hesse y Mann. (Nota del trad.) 
El Bildungsroman para no especialistas: Un intento...

No es improbable que uno de los agentes principales de este proceso fuese Erich Auerbach con su importante e influyente libro Mimesis de 1946. Esto es posible en tanto es considerado, especialmente en Estados Unidos, como uno de los fundadores de la literatura comparada y debido al carácter erudito, lúcido y persuasivo de sus argumentos, que incluso el experto Walter Bruford trató con consideración (1975: 153-154). Más recientemente, J. P. Stern ha dado otra muestra del perdurable prestigio de Auerbach (Stern, 1986). ${ }^{14}$ Que uno solo de los veinte capítulos de Mimesis se ocupe principalmente de un texto alemán es quizá ya un signo de la relativa indiferencia hacia la literatura alemana entre los comparatistas y los expertos en literatura general de los departamentos de inglés, con la excepción ocasional de Goethe, alguno que otro de los románticos, alguno que otro de los modernistas,${ }^{15} \mathrm{y}$ autores mediados por la teoría literaria francesa como Hölderlin y Nietzsche.

Este capítulo, como, supongo, se sabe, comienza con una discusión sobre el músico Miller de Intriga y amor de Schiller como una figura del "realismo burguéssentimental" (Auerbach, 1996: 410), para después presentar a la obra como el único ejemplo de su tipo en la literatura alemana y hablar, con un evidente matiz de remordimiento, sobre el fracaso de los alemanes en desarrollar una variante del realismo europeo. Auerbach asevera que Goethe posee una gran influencia en el siglo XIX, un supuesto que la historia literaria más reciente ha comenzado a cuestionar con razón (de nuevo, el objeto es visto a través de los lentes de la canonización guillermina). Por tanto, Auerbach comenta en términos bastante convencionales sobre la indiferencia de Goethe respecto a la realidad políticosocial y su "aversión hacia todo lo violento y explosivo" (1996: 419). Considero que su observación sobre la "calma casi atemporal" (Auerbach, 1996: 421) del Wilhelm Meister es incorrecta: la novela carece de un pronunciado sentido del espacio, pero no del tiempo, porque se sitúa de manera reconocible en el último cuarto del siglo XVIII. Su visión sobre la "inmovilidad" social de las Afinidades electivas (Auerbach, 1996: 423) fue desafiada por la crítica moderna, capaz de detectar las líneas subyacentes de dinámicas sociales en la novela (Vaget, 1980). Auerbach no trata directamente el problema del Bildungsroman, pero su resumen de la posterior historia de la literatura alemana en el siglo XIX evidentemente alude a este:

El desmenuzamiento y la limitación del realismo fueron iguales en sus contemporáneos más jóvenes y en las generaciones siguientes; hasta finales del sigloXIX, las obras más importantes que intentaron dar forma seriamente a temas de la sociedad de la época se mantuvieron en lo semifantástico o en lo idílico o, al menos, dentro de los estrechos límites de lo local y presentaron el cuadro de lo económico, social y político como algo estático (Auerbach, 1996: 425). ${ }^{16}$

14 Stern considera que el libro de Auerbach es la "obra de crítica literaria más importante del período de posguerra" (1986: 194) y hace contundentes afirmaciones sobre su presente y futura relevancia. Creo que uno puede admirarlo como un buen logro de su época sin perder el aliento por eso. En realidad, Stern está un poco incómodo con el análisis de literatura alemana de Auerbach, pero no creo que vea realmente el problema: así, en relación con el capítulo de Intriga y amor de Schiller, critica la visión restrictiva de la realidad que tiene Auerbach pero no su restrictiva historización literaria o lo que percibo como una compresión limitada de la obra de Schiller. Una postura más crítica e histórica puede encontrarse en Landauer (1988).

15 Cfr. nota 13. (Nota del trad.)

16 El énfasis es del autor. (Nota del trad.) 
Incluso en Fontane "el realismo social apenas si cala hasta el fondo, y el movimiento político en Gottfried Keller es pronunciadamente suizo" (Auerbach, 1996: 425). De manera algo inesperada, Auerbach vuelve a este tema en su capítulo sobre Germinie Lacerteux de los Goncourt. Aquí leemos:

De Alemania o, mejor, del territorio de habla alemana, ya nos ocupamos brevemente [...]. Pero cuando se piensa que Jeremias Gotthelf (nacido en 1797) sólo cuenta dos años más que Balzac, y Adalbert Stifter (1805) seis menos, que los coetáneos alemanes de Flaubert (1821) y Edmond de Goncourt (1822), son Freytag (1816), Storm (1817), Fontane y Keller (ambos en 1819), que los escritores de un cierto nombre, nacidos aproximadamente cuando Zola, o sea hacia 1840, se llamaban Anzengruber y Rosegger; todos estos nombres por sí solos bastan para demostrar que la vida en Alemania era mucho más provincianay anticuada, mucho menos al día (Auerbach, 1996: 484).

El resto del pasaje, que continúa por varias páginas, no tiene importancia aquí; fundamentalmente, contiene críticas acotadas de Hebbel, Keller, Fontane y Hauptmann. A lo largo del pasaje persiste un subtexto de evaluación canónica que invita a un análisis que no puede ser retomado aquí.

El punto es que no hay mención alguna de Willibald Alexis, de Karl Gutzkow, o de los novelistas "norteamericanos", Charles Sealsfield y Friedrich Gerstäcker. ${ }^{17}$ Wilhelm Raabe, el más cosmopolita e innovador de los realistas alemanes decimonónicos, es mencionado solo de pasada en conexión con La crónica del callejón de los gorriones y El pastor del hambre, sus obras más canónicas pero no las más maduras. Auerbach ha oído de Friedrich Spielhagen, pero solo observa que fue "completamente olvidado" (Auerbach, 1996: 485). No demuestra consciencia sobre el hecho que el olvido de Spielhagen fue producto de un desarrollo canónico particular; tampoco da cuenta de un conocimiento de primera mano de sus novelas.

Dos elementos pueden advertirse en este ya clásico testimonio. En primer lugar, Auerbach fue en sus orígenes un romanista, un medievalista y un renacentista. Su percepción sobre la historia literaria alemana está influida manifiestamente por el canon académico de su generación; esto es evidente por los autores que toma como representativos del canon: Jean Paul, Hoffmann, Gotthelf, Stifter, Hebbel y Storm. Si todos ellos son social y políticamente tan inactivos, idílicos o locales como se enuncia que son es un asunto que no puede ser estudiado aquí, pero es posible que estos autores no sean las mejores o las únicas opciones para una discusión sobre el realismo en la literatura alemana del siglo XIX. En segundo lugar, se debe recordar que Mimesis fue escrita en el exilio en Estambul, donde Auerbach tenía un número limitado de libros a su disposición. Él era consciente

17 Tanto la producción de Charles Sealsfield, pseudónimo del austríaco Carl Anton Postl (1793-1864), como la del cosmopolita Friedrich Gerstäcker (1816-1872) pueden inscribirse en el terreno de la literatura de viaje, con novelas, diarios y otros escritos que tratan diferentes espacios, entre los que se destaca el estadounidense. Así, el primero de ellos asume en Estados Unidos no solo su identidad literaria sino que también su oficio en la esfera pública como corresponsal y periodista, adquiriendo en su último viaje la ciudadanía estadounidense, mientras que las novelas más reconocidas de Gerstäcker -inaccesibles en español- delatan su afiliación temática con Estados Unidos y la tradición novelística de James Fenimore Cooper ya desde sus títulos: Los reguladores en Arkansas (1846) y Los piratas del río Mississippi (1847) (nota del trad.). 
de esta limitación pero también pensaba que esto podría suponer una ventaja: "es muy posible también que el libro deba su existencia precisamente a la falta de una gran biblioteca sobre la especialidad; si hubiera tratado de informarme acerca de todo lo que se ha producido sobre temas tan múltiples, quizá no hubiera llegado nunca a poner manos a la obra" (Auerbach, 1996: 525).

Sin embargo, no es la falta de bibliografía secundaria la que limita el alcance de su capítulo sobre realismo alemán, sino la de bibliografía primaria: simplemente no había leído suficiente. Esto no pretende ser una crítica de Auerbach: la recanonización no es una tarea para generalistas sino para especialistas, una importante razón por la que son necesarios en el campo de estudios de literatura alemana. Pero no es solo Auerbach, toda la comunidad humanística aceptó el estrecho canon de la Germanística por mucho tiempo. Desde entonces se ha vuelto cada vez más evidente que la historia literaria alemana puede ser aprehendida de formas bastante diferentes y más completas. Pero, debido a la periferia de la literatura alemana en los estudios de literatura general y comparada, las nuevas iniciativas no han penetrado mucho más allá de los límites de la Germanística, de lo que creo es en gran parte responsable de la confusión en el empleo del término Bildungsroman.

En este sentido, tengo una preferencia que no pretendo imponer a otros pero que podría contribuir a hacer que la palabra Bildungsroman sea un término de alguna utilidad para la crítica literaria y no un mero "ruido". El Bildungsroman tiene que estar ligado al concepto de Bildung, esto es, con el concepto de la temprana burguesía humanista sobre el desarrollo del yo individual desde sus potencialidades innatas hasta el umbral de la madurez, a través de un proceso de adaptación y experiencia cultural y social. El concepto emerge en el mismo momento en que el pensamiento alemán comienza a adquirir relevancia en la cultura occidental, y logra gran resonancia histórica; por ejemplo, subyace en el principio de educación liberal de la educación norteamericana, aunque este principio sea más respetado en la ceremoniosa retórica académica que en la práctica educativa. Una novela que es clasificada como un Bildungsroman debería, pues, sostener cierto contacto con este concepto.

No importa demasiado si el proceso de Bildung es exitoso o no, si el protagonista logra o no acomodarse a la vida y a la sociedad. Así, los Antibildungsromane de los románticos, y la versión paródica de la literatura del siglo XX, desde Thomas Mann a Günter Grass, pueden ser incluidos dentro de esta serie genérica (Selbmann, 1984: 40). Pero Bildung no es mera acumulación de experiencia ni el paso a la madurez bajo la forma de una biografía ficticia. Debe tener un sentido de cambio evolutivo dentro del propio yo, una teleología de la individualidad, incluso si la novela, como sucede con frecuencia, pone en duda o niega la posibilidad de alcanzar un resultado satisfactorio. Ciertamente, puede tratarse al Bildungsroman como un tipo ideal que no tiene que necesariamente mantener contacto con la tradición novelística alemana o la Humanitätphilosopie de la época de Goethe y Humboldt, pero considero que cuanto más se aleja uno de estas raíces, mayor cuidado debe tenerse al definir el término y justificar su utilidad. 
Por tanto, diría que David Copperfield es un Bildungsroman; Jude el oscuro, quizá; Rojo y negro, quizá; Las ilusiones perdidas, no. El efecto de mi propuesta sería circunscribir considerablemente la aplicabilidad del término manteniéndolo dentro de los límites de su contexto histórico y especialmente ideológico, porque el concepto de Bildung es fundamentalmente burgués: implica muchos supuestos sobre la autonomía y relativa integridad del yo, sus potenciales energías auto-creativas, su relativo rango de opciones dentro de las determinaciones materiales, sociales, incluso psicológicas. Puede ser que en el mundo moderno se haya vuelto cada vez más difícil, fuera de la pura ideología y el mito, sostener estos supuestos; como he intentado mostrar, incluso en la novela alemana del siglo XIX se hicieron rápidamente bastante difíciles de sostener (Sammons, 1981).

Para la época de la fundación del imperio se había hecho evidente que el ideal de Bildung se había vuelto obsoleto (Köhn, 1969: 39). Este desarrollo lo podemos ver en el excelente estudio sobre la historia del concepto de Bildung de Bruford: los únicos Bildungsromane decimonónicos que estudia después de Wilhelm Meister son El verano tardío de Stifter y el accidentado Uno también de Friedrich Theodor Vischer para luego tratar La señora Jenny Treibel de Fontane que no es, por supuesto, un Bildungroman, sino una sátira sobre la degeneración del ideal de Bildung entre la advenediza burguesía con sus "falsas pretensiones de cultura" (Bruford, 1975: 194). Este proceso es aún más claro en nuestro siglo: Werner Welzig, quien comienza su introducción a la novela alemana del siglo XX con un extenso capítulo sobre el Entwicklungsroman, comenta que el concepto de Bildungsroman se ha tornado inadecuado "porque los principios de una posible educación o Bildung se han vuelto dudosos" (Welzig, 1970: 11).

Esto me lleva a ciertas proposiciones comprobables sobre la literatura alemana del siglo XIX que desearía puedan ser comunicadas a las disciplinas literarias en general. El Bildungsroman no fue el modo dominante de la novela, sino un subgénero periférico, ocasional y generalmente con una realización imperfecta; como se señaló, fue la discusión sobre Bildung y Bildungsroman lo que tuvo un lugar especial en Alemania (Vosskamp, 1986: 24). Los modos predominantes fueron la novela histórica y la novela social y política. En este sentido, la literatura alemana estaba mucho menos alienada del contexto europeo de lo que los alemanes hicieron creer posteriormente. Es interesante que el reconocimiento de este hecho corra paralelo a un desarrollo en historiografía que está comenzando a cuestionar el concepto de la peculiaridad alemana, el presunto Sonderweg que supuestamente distinguía Alemania de todas las otras naciones europeas en el Oeste y el Este. ${ }^{18}$

Puede ser que haya un déficit cualitativo en la novela alemana en comparación con sus contrapartes inglesas, francesas, estadounidenses y rusas; y es aún más probable que haya algo de verdad en la creencia, basada en las propias percepciones de los observadores del siglo XIX, de que este déficit está relacionado con las particularidades del contexto alemán: el orden social relativamente más estático, 
la falta de una ciudad capital, el fracaso traumático de la revolución de 1848, etc. No se debe olvidar que, por gran parte del siglo, los escritores alemanes tuvieron que bregar con una censura persistentemente opresiva. Como suele ser el caso con la historia literaria, algunas de las obras más reconocidas en su propio tiempo son incapaces de impresionarnos demasiado hoy; en muchos casos, exhiben inquietantes complicidades con la evolución de la sociedad alemana hacia sus catástrofes histórico-mundiales en nuestro siglo. ${ }^{19}$

Pero la excepcional excelencia estética, aunque no es irrelevante, no es una prioridad dominante en la historiografía literaria. Incluso si es cierto -lo cual estoy lejos de creer que sea el caso- que "la mayor parte de la escritura novelística alemana de importancia participa en este [el Bildungsroman] constructo genérico" (Swales, 1978: 23), este es un principio de selectividad canónica y no de historia literaria. ${ }^{20}$ En el siglo XIX hay mucha escritura digna, interesante, en muchos casos innovadora, especialmente en el género de la novela, que sencillamente fue olvidada.

La historia de la teoría de la novela y la crítica entre la Restauración y el realismo programático muestra que la novela histórica sucesora de Walter Scott, la novela política de la Joven Alemania y la novela social o la novela de aldea, ${ }^{21}$ en efecto, hace mucho tiempo que habían relegado a un segundo plano a la Individualroman de la tradición del Wilhelm Meister, tanto en lo que respecta a la producción literaria como crítica (Selbmann, 1984: 28).

Al menos, necesitamos emanciparnos de la noción de que el tono de las letras alemanas decimonónicas fue marcado en gran parte por un semiermitaño introvertido como Mörike, un depresivo como Storm, un escamoteador desesperado de la experiencia y la percepción como Stifter o un fundamentalista religioso como Gotthelf; de que el tono era provincial, quiescente, nostálgicamente idílico, que se hallaba "por encima" de la agitación de la sociedad y la política, y que estaba afligido de forma sombría por la ansiedad de la influencia de Goethe y los románticos.

La vida literaria era activa y variada, y estaba abierta a las influencias cosmopolitas e internacionales. Muchas de estas influencias eran inglesas y hasta cierto punto estadounidenses, pero podemos sentir la presencia de modelos extranjeros, de Turguénev a Zola. La literatura alemana no solo recibía influencias sino que también las creaba: la cantidad de atención que recibían los desarrollos literarios alemanes en el siglo XIX, de San Petersburgo a San Francisco, parece

19 La consecuencia de esta circunstancia es que la actitud académica moderna hacia gran parte de la literatura alemana decimonónica es más una de acusación que de aprecio, en un nivel que puede no ser el caso en nuestras disciplinas hermanas. Menciono esto para informar a aquellos menos familiarizados con nuestro campo pero creo que es un contraste que podría atraer la atención de los comparatistas más de lo que lo ha hecho hasta al momento.

20 De hecho, fue sugerido por Selbmann (1984: 36) que la novela trivial del siglo XIX tendió hacia la forma del Bildungsroman y que muchos ávidos novelistas evitaron la forma con el objeto de escapar la acusación siempre amenazante de trivialidad.

21 En al. Dorfroman. (Nota del trad.) 
El Bildungsroman para no especialistas: Un intento...

bastante notable en comparación con el relativo silencio de hoy en día. La confusión, indiferencia y arbitrariedad que rodea el empleo del término Bildungsroman es un síntoma de estas conexiones pérdidas.

A lo mejor, sin embargo, es inútil intentar disciplinar el empleo del término; la música seguirá sonando, no importa lo que nosotros tengamos para decir al respecto. El lector recordará la extraña utilización del término Bildungsroman que hace Irving Howe al hablar de un ballet. En el New York Times del 25 de marzo de 1988, un aviso sobre la adaptación cinematográfica de la obra de Neil Simon, Biloxi Blues, fue intitulado como "Bildungsroman en los Cuarteles". 


\section{Bibliografía}

"Adler, H. (1980). Soziale Romane im Vormärz: Literatursemiotische Studie. Múnich: Fink.

"Auerbach, E. (1996). Mimesis: La representación de la realidad en la literatura occidental. Trad. J. Villanueva y E. Ímaz. México: Fondo de Cultura Económica.

" Bajtín, M. M. (1995). La novela de educación y su importancia en la historia del realismo. En Estética de la creación verbal, pp. 200-247. Trad. de T. Bubnova. Madrid: Siglo XXI.

"Blackbourn, D. y Eley, G. (1984). The Peculiarities of German History: Bourgeois Society and Politics in Nineteenth Century Germany. Oxford: Oxford University Press.

" Borcherdt, H. H. (1958). Bildungsroman. En Kohlschmidt, W. y Mohr, W. (eds.). Reallexikon der deutschen Literaturgeschichte. Berlín: de Gruyter.

"Buckley, J. H. (1974). Season of Youth: The Bildungsroman from Dickens to Golding. Cambridge: Harvard University Press.

" Bruford, W. H. (1975). The German Tradition of SelfCultivation: Bildung'from Humboldt to Thomas Mann. Cambridge: Cambridge University Press.

" Denkler, H. (ed.). (1980). Romane und Erzählungen des bürgerlichen Realismus: Neue Interpretationen. Sttugart: Reclam.

" Friesen, G. (1972). The German Panoramic Novel of the 19th Century. Frankfurt/M: Herbert Lang.

" Howe, I. (1988). News from Elsewhere. En New York Review of Books, s.p. Reseña de Arabescos de Anton Schammas, publicada el 14 de abril.

" Huber, H. D. (1978). Historische Romane in der ersten Hälfte des 19. Jahrhunderts: Studie zu Material und, schöpferischen Akt' ausgewählter Romane von A. v. Arnim bis A. Stifter. Múnich: Fink.

" Jackson, P. (1981). Bürgerliche Arbeit und Romanwirklichkeit: Studien zur Berufsproblematik in Romanen des deutschen Realismus. Frankfurt/M: R. G. Fischer.

" Jacobs, J. (1972). Wilhelm Meister und seine Brüder: Untersuchungen zum deutschen Bildungsroman. Múnich: Fink.

"Kaiser, N. A. (1986). Social Integration and Narrative Structure: Patterns of Realism in Auerbach, Freytag, Fontane, and Raabe. Nueva York: Peter Lang.

"Kafitz, D. (1978). Figurenkonstellation als Mittle der Wirklichkeitserfassung. Dargestellt an Romanen der zweiten Hälfte des 19. Jahrhunderts: Freytag, Spielhagen, Fontane, Raabe. Kronberg: Athenäum.

" Köhn, L. (1969). Entwicklungs und Bildungsroman: Ein Forschungsbericht. Sttugart: Metzler.

"Kolbe, J. (1968). Goethes ,Wahlverwandtschaften' und der Roman des 19. Jahrhunderts. Sttutgart: Kohlhammer.

" Landauer, C. (1988). Mimesis and Erich Auerbach's Self Mythologizing. German Studies Review, vol. 1, pp. 83-96.

" Lützeler, P. M. (ed.). (1983). Romane und Erzählungen zwischen Romantik und Realismus: Neue Interpretationen. Sttugart: Reclam. 
El Bildungsroman para no especialistas: Un intento...

" Mann, T. (1978). De la creencia. En_. Consideraciones de un apolítico, pp. 503-548. Trad. de L. Mames. Barcelona: Grijalbo.

" Mann, T. (1960). Gesammelte Werke, XI. Frankfurt/M: S. Fischer.

" May, K. (1957). Wilhelm Meisters Lehrjahre, ein Bildungsroman? En Deutsche Vierteljahrsschrift, vol. 31, núm. 1, pp. 1-37.

"Peschken, B. (1984). Versuch einer germanistischen Ideologiekritik: Goethe, Lessing, Novalis, Tieck, Hölderlin, Heine in Wilhelm Diltheys und Julian Schmidts Vorstellungen. Stuttgart: Metzler.

"Sammons, J. L. (1981). The Mystery of the Missing Bildungsroman or: What Happened to Wilhelm Meister's Legacy? En Genre, vol. 14, pp. 229-46.

"Sammons, J. L. (1973). Hermann Hesse and the Over Thirty Germanist. En Ziolkowski, T. (ed.). Hesse: A Collection of Critical Essays. Nueva Jersey: Prentice-Hall.

"Selbmann, R. (1984). Der Deutsche Bildungsroman. Sttugart: Metzler.

"Steinecke, H. (1984). Romantheorie und Romankritik in Deutschland. Sttugart: Metzler

" Stern, J. P. (1986). In Praise of Erich Auerbach's Mimesis. En Stern, J. P. (ed.), London German Studies III, pp. 194-211. Londres: University of London.

"Swales, M. (1978). The German Bildungsroman from Wieland to Hesse. Princeton: Princeton University Press.

"Vaget, H. R. (1980). Ein reicher Baron: Zum sozialgeschichtlichen Gehalt der ,Wahlverwandstchaften'. En: Jarhbuch der Deutschen Schillergesellschaft, vol. 24, pp. 123-161.

" Vosskamp, W. (1986). Der Bildungsroman als literarischsoziale Institution in Deutschland. (Zur Begriffs und Funktionsgeschichte des Bildungsromans am Ende des 18. und Beginn des 19. Jahrhunderts). En Wagenknecht, Ch. (ed.), Zur Terminologie der Literaturwissenschaft, pp. 337-352. Stuttgart: Metzler.

"Welzig, W. (1970). Der deutsche Roman im 20. Jahrhundert. Sttugart: Kröner.

"Worthmann, J. (1974). Probleme des Zeitromans: Studien zur Geschichte des deutschen Romans im 19. Jahrhundert. Heildelberg: Carl Winter.

"Ziolkowski, T. (1965). The Novels of Hermann Hesse. Princeton: Princeton University Press. 